\title{
The Metal-Thiolate Clusters of Plant Metallothioneins
}

\author{
Eva Freisinger*
}

\begin{abstract}
While structures of mammalian metallothioneins and their metal-thiolate clusters have been known for nearly 20 years, the first three-dimensional structure of a plant metallothionein was only published very recently. Also in other aspects, research on plant metallothioneins lags behind what is known about the vertebrate forms. However, in the past years more and more information, mostly based on experiments performed with optical spectroscopy has become available and permit sometimes unforeseen insights. In the following, the different experimental strategies applied in our laboratory will be described together with the progress we have made over the past years in detecting and characterizing the metal-thiolate clusters of plant metallothioneins.
\end{abstract}

Keywords: Bioinorganic chemistry · LMCT bands · Metal-thiolate cluster · Plant metallothioneins . Spectroscopy

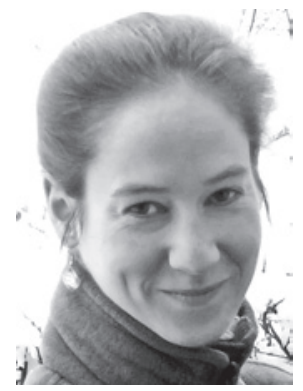

Eva Freisinger studied chemistry at the University of Dortmund, Germany, where she also completed her PhD in bioinorganic chemistry in the group of Bernhard Lippert (2000). After a postdoctoral stay at the SUNY

Stony Brook, NY, in the field of structural biology with Caroline Kisker (2000-2003) she joined the group of Heinz Berke at the Institute of Inorganic Chemistry of the University of Zürich as an Oberassistent, where she started to investigate the metallothioneins of plants (2003). In 2008, Eva Freisinger was awarded a Förderungsprofessur of the Swiss National Science Foundation.

\section{Introduction}

\subsection{The Superfamily of Metal- lothioneins}

Metallothioneins (MT) are a ubiquitous class of proteins with an extremely high cysteine content, which can reach up to $30 \%$ of the total amino acid content in the vertebrate forms. The sheer number of potential metal-coordinating ligands in the form of soft thiolate groups strongly suggest a pronounced metal binding ability, and indeed, thioneins, the metal-free apo-forms of the proteins, soak-up certain metal ions like a sponge. Due to their thiophilicity, metal ions with the electronic configuration $d^{10}$ such as $\mathrm{Zn}^{\mathrm{II}}, \mathrm{Cu}^{\mathrm{I}}, \mathrm{Cd}^{\mathrm{II}}$, and $\mathrm{Hg}^{\mathrm{II}}$ are the preferred binding partners, but also other metal ions e.g. $\mathrm{Mn}^{\mathrm{II}}$, $\mathrm{Fe}^{\mathrm{II}}, \mathrm{Co}^{\mathrm{II}}, \mathrm{Ni}^{\mathrm{II}}, \mathrm{Pt}^{\mathrm{II}}, \mathrm{Pb}^{\mathrm{II}}$, and $\mathrm{As}^{\mathrm{III}}$ have been found to bind to MTs although mostly under in vitro conditions. ${ }^{[1-7]}$ The divalent metal ions that are most frequently found associated with MTs in vivo are $\mathrm{Zn}^{\mathrm{II}}$ and $\mathrm{Cd}^{\mathrm{II}}$. Both metal ions are found in tetrahedral tetrathiolate coordination environments (Fig. 1A). Metal ion coordination proceeds concurrently with deprotonation of the cysteine (Cys) thiol groups. This reaction can occur at physiological or even slightly acidic $\mathrm{pH}$ due to the decrease of the apparent $\mathrm{p} K$ value of the Cys thiol groups from usually $\sim 8.5$ by $4-5 \log$ units in the presence of the respective metal ions. MTs are able to bind a significantly higher amount of metal ions than one would expect assuming solely coordination in isolated or separated $\mathrm{M}^{\mathrm{II}} \mathrm{Cys}_{4}$ sites, and they do so by forming cluster structures. Classically, the term cluster specifies an accumulation of atoms, in which two or more metal ions are directly connected to each other via a metal-metal bond. In addition, also other non-metals may be bound to and/or bridge these metal ions. The clusters of MTs are, however, not clusters in the above sense but rather multinuclear coordination compounds of the Werner-type, hence without direct metal-metal bonds. Cluster formation in MTs, marked by the appearance of bridging thiolate groups (Fig. 1B), becomes relevant when the ratio of metal ions to thiolate groups exceeds $1: 4$, hence when the availability of free thiol groups becomes limiting. Much has been speculated and published to address the question if metal binding to MTs is governed by positive cooperativity, i.e. that binding of the first metal ion enhances the binding of the second metal ion and so forth. ${ }^{[8-10]}$ It is relatively save to say that the extreme form of positive cooperativity, the presence of only metal-free and fully metal ion-loaded proteins will not have physiological relevance for MTs. But also the opposite, the strictly stepwise coordination of metal ions in separate binding sites at first and formation of oligonuclear aggregates only when the supply of ligands becomes limiting, might be too much of a simplification. Indeed, there might be structures that promote cluster formation in a part or domain of a given MT even if free Cys thiol groups are still available (Fig. 1B, alternative formation path in brackets). ${ }^{[10,11]}$

Concerning the role of MTs in living organisms, the precise function remains elusive. The high metal ion binding capacity of MTs suggests a role in metal ion storage, metabolism and trafficking of essential $\mathrm{Cu}^{\mathrm{I}}$ and $\mathrm{Zn}^{\mathrm{II}}$ ions, as well as the detoxification of non-essential metal ions such as $\mathrm{Cd}^{\mathrm{II}}$ and $\mathrm{Hg}^{\mathrm{II}}{ }^{\left[{ }^{[12]} \text { Consider- }\right.}$ ing the thermodynamic stability of the 


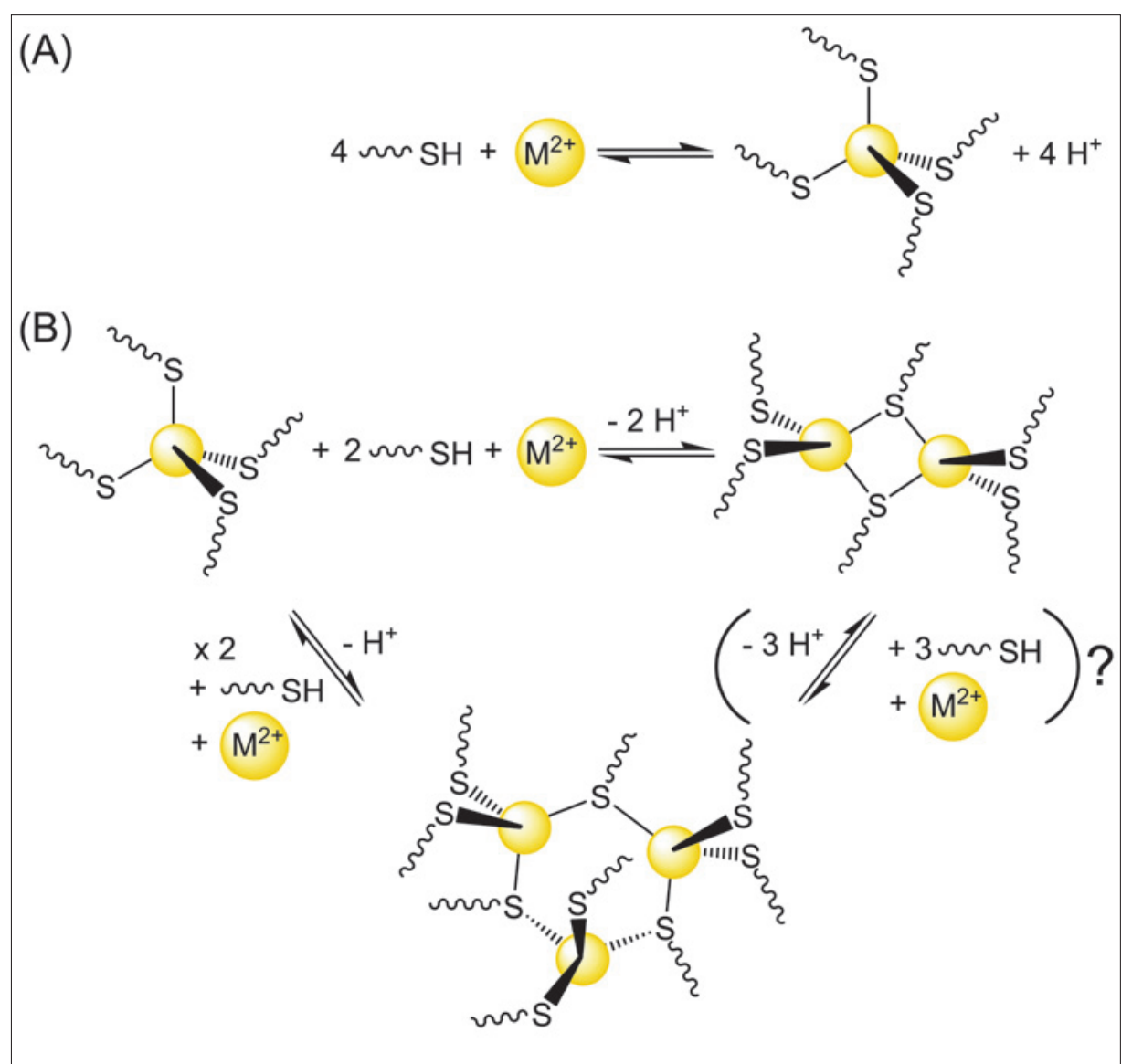

Fig. 1. Coordination of divalent metal ions by MTs. (A) Initially, divalent metal ions are coordinated by four terminal thiolate groups of Cys residues concurrently with deprotonation of the ligands. (B) When the amount of ligands becomes limited, the maximum binding ability is achieved by additionally recruiting bridging thiolate ligands. Cooperativity in metal-thiolate cluster formation is still a subject of ongoing discussions (alternative reaction path in brackets).

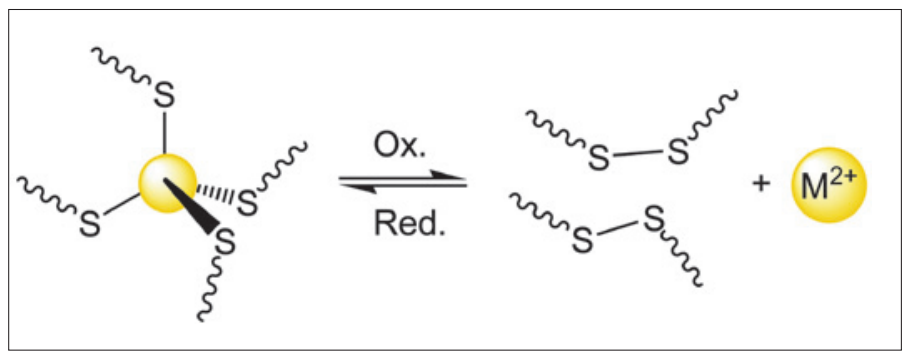

Fig. 2. Oxidation of the Cys thiolate ligands in MTs leads to the formation of disulfide bridges and release of coordinated metal ions. The process is reversible.

metal-thiolate clusters combined with a pronounced kinetic lability, such a role in the homeostasis of metal ions becomes even more probable. An attractive view is also the perception that MTs not only soak-up toxic metal ions, but might even 'repair' the adverse effects of heavy-metal poisoning of enzymes by exchanging $e . g$. $\mathrm{Cd}^{\mathrm{II}}$ again for $\mathrm{Zn}^{\mathrm{II}}{ }^{[13]}$ Additional effects observed for some MT forms include neuronal growth inhibitory activity, ${ }^{[14]}$ resistance development against platinum anti-cancer drugs, ${ }^{[15]}$ as well as antioxidative properties and relevance in reactive oxygen species (ROS) scavenging. ${ }^{[16]}$ The latter can be understood in light of the relative oxidation sensitivity of the thiol(ate) groups in MTs. On the one hand, the free thiol groups in the apo-protein are prone

\subsection{Three-Dimensional Structures of Metal-Thiolate Clusters}

Today, a number of three-dimensional structures of different metal-thiolate clusters are known, mostly determined by NMR spectroscopy. Structure determination with single crystal X-ray crystallography only succeeded in two cases, ${ }^{[18,19]}$ the small number probably originating from a high degree of flexibility of the parts of the peptide chain not associated with the metal cluster, as MTs are generally characterized by a lack of secondary structural elements. Fig. 3 depicts the three-dimensional structures of the different metal-thiolate cluster types of MTs known today. The list starts with an exception as $\mathrm{Zn}_{2}$ - or $\mathrm{Cd}_{2} \mathrm{Cys}_{6}-$ clusters were so far only structurally characterized in the group of fungal and yeast transcription factors, ${ }^{[20,21]}$ but there are nevertheless strong indications that a $\mathrm{Cd}_{2}$ Cys arrangement can be also found in the $\gamma$-domain of the Triticum aestivum (wheat) MT Zn $\mathrm{E}_{6}-1$ (Fig. 3A). [11] Clusters of the form $\mathrm{M}_{3}{ }_{3}^{\mathrm{I}} \mathrm{Cys}_{9}$, commonly designated as $\beta$-clusters, are found in vertebrate, crustacean, and echinodermata MTs, as well as in the $\beta_{\mathrm{E}}$-domain of the above-mentioned wheat $\mathrm{Zn}_{6} \mathrm{E}-1$ (Fig. 3B,C). ${ }^{[18,22-24]}$ Clusters with four divalent metal ions, $\mathrm{M}_{4}^{\mathrm{II}} \mathrm{Cys}_{11}$ or $\mathrm{M}_{4}^{\mathrm{II}} \mathrm{Cys}_{9} \mathrm{His}_{2}$, are called $\alpha$-clusters and are part of vertebrate, echinodermata, as well as cyanobacterial MTs (Fig. 3D,E). ${ }^{[18,24,25]}$ Cyanobacterial $\mathrm{Zn}_{4} \mathrm{SmtA}$ was the first structure of a MT that revealed participation of histidine (His) residues in the coordination of metal ions. The only known structure of a metal-thiolate cluster with monovalent metal ions is the one of the $\mathrm{Cu}^{\mathrm{I}}$-specific MT CUP1 from yeast (Fig. 3F). ${ }^{[19]}$ The solid-state structure of a slightly truncated form shows an $\mathrm{Cu}_{8} \mathrm{Cys}_{10}$ arrangement, in which six $\mathrm{Cu}^{\mathrm{I}}$ ions have a trigonal planar and two a linear coordination sphere formed by thiolate ligands. CUP1 is the only structurally characterized MT so far, in which apparently not all Cys residues take part in metal ion coordination, namely the two C-terminal Cys residues. However, it cannot be excluded that they play a role in $\mathrm{Cu}^{\mathrm{I}}$ uptake to or release from the cluster and could not be localized in the solution structure due to a high degree of flexibility. Naturally, the metal ion binding capacity of MTs per Cys residue is higher for monovalent metal ions, i.e. 0.8 $\mathrm{M}^{\mathrm{I}}$ per Cys, than for divalent metal ions, i.e. $0.33-0.36 \mathrm{M}^{\mathrm{II}}$ per Cys.

\subsection{Plant Metallothioneins}

Being known for 50 years, ${ }^{[26]}$ the vertebrate MTs constitute certainly the best studied MT family. The discovery of the first Cys-rich protein from a plant already dates back more than 25 years, although the comprehension that the early Cys-la- 


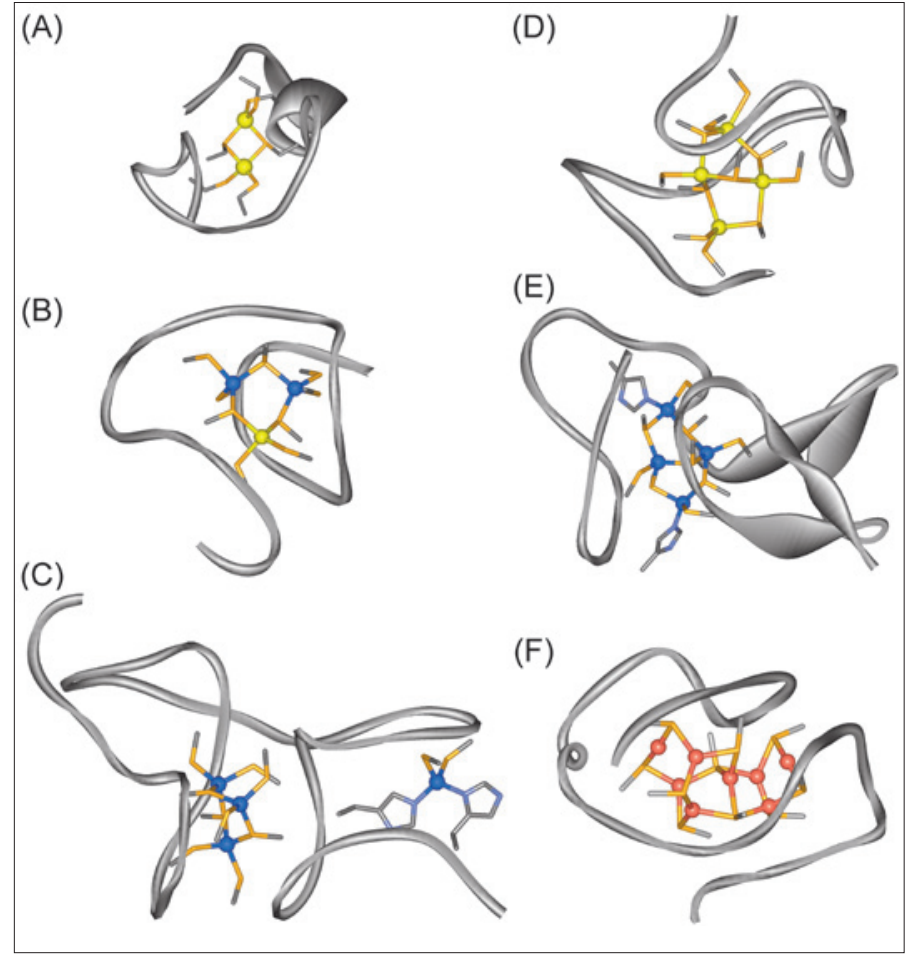

Fig. 3. Three-dimensional structures of metal-thiolate clusters as determined by NMR spectroscopy (A, C, E) or X-ray crystallography (B, D, F): (A) $\mathrm{Cd}_{2}$-domain of fungal LAC9 transcriptional activator (PDB code 1CLD), ${ }^{[20]}$ (B) CdZn 3 -domain of rat $\mathrm{Cd}_{5} \mathrm{Zn}_{2} \mathrm{MT2}$ (4MT2), ${ }^{[18]}$ (C) $\mathrm{Zn}_{4} \beta_{\mathrm{E}}$-domain of wheat $\mathrm{Zn}_{6} \mathrm{E}_{c}-1$ (2KAK), ${ }^{[23]}$ (D) $\mathrm{Cd}_{4} \alpha$-domain of rat $\mathrm{Cd}_{5} \mathrm{Zn}_{2} \mathrm{MT2}$ (4MT2), ${ }^{[18]}$ (E) structure of cyanobacterial $\mathrm{Zn}_{4} \mathrm{SmtA}$ (1JJD), ${ }^{[25]}$ (F) structure of yeast $\mathrm{Cu}_{8} \mathrm{CUP} 1$ (1RJU). ${ }^{[19]}$ belled protein found in wheat seeds, wheat $\mathrm{E}_{\mathrm{c}}-1$, could be actually grouped into the superfamily of MTs took some time. ${ }^{[27,28]}$ But still, it is more than surprising how little we know about plant MTs even today, especially as they emerged to form one of the most, if not the most, diverse families of MTs we know. Fig. 4 shows sequence alignments of the amino acid chains of some typical members of the vertebrate MT family and in comparison sequences from the four subfamilies of plant MTs. The high Cys content of all forms is obvious, and one of the main distinguishing factors from other protein classes. Additional attention attract the long Cys-free stretches between the $\mathrm{N}$ - and $\mathrm{C}$-terminal Cys-rich regions in the plant MT subfamilies p1, p2, and p3, commonly known as linker regions. Only speculations exist about the function or usefulness of these linker regions, ranging from a role in protein targeting to a purely connecting function in a precursor protein that is transformed into its predominant form in vivo only after proteolytic cleavage of the linker. Noticeable is further the occurrence of aromatic amino acids within these linker regions, which are strictly absent in vertebrate MTs. In addition His residues can be found, also in contrast to

\section{vertebrate MTs

$\begin{array}{ll}\text { MT1 } & \text { (M. musculus) } \\ \text { MT2 } & \text { ( } H . \text { sapiens) } \\ \text { MT2 } & \text { ( } R . \text { norvegicus) } \\ \text { MT3 } & \text { (M. musculus) } \\ \text { MT4 } & \text { (M. musculus) }\end{array}$ \\ MT 4 (M. musculus)}

\section{plant MTs}

subfamily p1

MT1 (C. arietinum)

MT1 (P. sativum)

MT1 (T. durum)

MT1A* (A. thaliana)

subfamily p2

$$
\begin{array}{ll}
\text { MT2 } & \text { (C. arietinum) } \\
\text { MT2 } & \text { (Q. suber) } \\
\text { MT2* } & \text { (M. acuminata) } \\
\text { MT2A } & \text { (A. thaliana) }
\end{array}
$$

subfamily p3

$$
\begin{array}{ll}
\text { MT3 } & \text { ( } A \text {. chinensis) } \\
\text { MT3 } & \text { (M. domestica) } \\
\text { MT3 } & \text { (M. acuminata) } \\
\text { MT3* } & \text { (A. thaliana) }
\end{array}
$$

subfamily pec

$$
\begin{array}{ll}
\mathrm{E}_{c} & (\text { Z. mays }) \\
\mathrm{E}_{\mathrm{c}}-1 & (\text { T. aestivum }) \\
\mathrm{E}_{\mathrm{c}}-1 & (\text { A. thaliana }) \\
\mathrm{E}_{\mathrm{c}}-2 & (\text { A. thaliana }) \\
\mathrm{E}_{\mathrm{c}} & (S . \text { indicum })
\end{array}
$$

Fig. 4. Amino acid sequence alignment of representative members of the vertebrate MT family as well as of the four subfamilies p1, p2, p3, and pec of plant MTs. Cys residues are accentuated with a black, aromatic amino acids with a grey background. His residues are framed with a black border. Sequences denoted with * represent exceptions to the otherwise highly conserved Cys distribution pattern within a plant MT subfamily. In A. thaliana MT1A the linker region is additionally reduced to just seven amino acids. 
vertebrate MTs, whose positions in the amino acid sequence can even display a high degree of conservation as in the $\mathrm{E}_{\mathrm{c}}$ proteins. Classification of plant MTs into the different subfamilies is based on the Cys distribution pattern in the N-terminal region. In contrast, the pattern found in the C-terminal Cys-rich region is highly conserved. The members of the pec subfamily stick out as they contain three Cys-rich regions, shorter linker regions, and two highly conserved His residues but usually no other aromatic amino acids.

The major part of plant MT research deals with gene expression studies, hence the detection and quantification of MT mRNA levels in plants or specific plant tissues at different developmental stages or under the influence of certain external and internal stimuli. [29-31] From these it can be deduced that members of the $\mathrm{p} 1$ subfamily have a higher tendency to be expressed in root tissue, $\mathrm{p} 2$ proteins in the aerial parts of the plant, $\mathrm{p} 3$ proteins in fleshy fruits, if the plant produces any, and the pec MTs in certain seeds. That the occurrence of especially the members of the $\mathrm{p} 1, \mathrm{p} 2$, and p3 subfamilies is not restricted to these tissues was depicted very clearly in one of the extremely rare publications on plant MT proteins directly detected in vivo. ${ }^{[32]}$ As a result, MTs from each of the three subfamilies were concomitantly found in all plant parts of Arabidopsis thaliana seedlings analysed, although preferences for certain tissues were obvious. As it is more than difficult if not hypothetical to deduce possible functions from such general results, one has to resort to more nongeneric studies to decipher the importance of MTs for a plant. For example, evaluating the transcription of the $m t 3 a$ gene in leaves of Elaeis guineensis (oil palm), no transcription was detected in normal leaves while distinct up-regulation occurs during leaf senescence. ${ }^{[33]}$ This led to the conclusion that plant MTs might have a role in scavenging released metal ions during catabolism of proteins and in this way prevent further damage by such free reactive metal ions. Alternatively or in addition, in this way oil palm MT3a could also serve as a storage for essential metal ions to be used for new foliation. Transcription of MT genes can also be triggered by elevated levels of metal ions suggesting a protecting and detoxifying role. However, metal-inducibility of plant MT genes is not always observed, e.g. the seed-specific $\mathrm{Zn}^{\mathrm{II}}$-thionein $\mathrm{E}_{\mathrm{c}}-1$ is rather overexpressed in response to the plant growth hormone abscisic acid than upon addition of $\mathrm{Zn}^{\mathrm{II}}$ or $\mathrm{Cd}^{\mathrm{II}}$ ions. In light of the major metal ion detoxifying machinery of plants, a group of enzymatically synthesized peptides commonly known as phytochelatins, detoxification by plant MTs might be of less importance. ${ }^{29]}$ It was however found as well that two MTs from $A$. thaliana are apparently able to complement the function of phytochelatins to a certain extent.[34]

\section{Source of Protein Material}

Considering the amount of different plant MT sequences available in the databases it is astonishing how little we know about the expressed proteins. One explanation might be that so far only the wheat $\mathrm{E}_{\mathrm{c}}-1$ protein could be directly isolated from plant material in sufficient amounts to allow an early characterization of the protein. ${ }^{[28]}$ Other attempts, e.g. the overexpression of MT1 from Pisum sativum (garden pea) in Escherichia coli were abandoned early due to observed proteolytic digestion of the linker region, and only a preliminary investigation of the protein was published. ${ }^{[35]}$ To circumvent the known problem of proteolytic digestion of peptides and small proteins in $E$. coli, overexpression in the form of fusion proteins with larger protein-tags has become common procedure in recent years. For this approach, the glutathion-S-transferase (GST) tag is frequently used (GE Healthcare, Amersham, Buckinghamshire, UK), which offers the additional benefit of affinity-tag purification using a glutathion Sepharose-4B column (GE Healthcare). If desired, the tag can be proteolytically cleaved after purification, e.g. using thrombin. It is also becoming more and more popular to use an engineered TEV protease site, as TEV, a cysteine protease from the tobacco etch virus, has a far more stringent sequence specificity than thrombin. ${ }^{[36]}$ Another advantage gaining importance when large-scale production of protein material for structural analyses is required, is the relatively straightforward overexpression and purification of the TEV protease itself. Experiments in our lab show that plant MTs from all four subfamilies can be overexpressed and purified with a GST-tag. However, efficiency of the subsequent proteolytic cleavage step with thrombin increases dramatically after treatment of the fusion protein with EDTA. We attribute this observation to the close distance of the metal-thiolate cluster(s) formed to the protease recognition site impeding proper binding and hence cleavage significantly. Considering that the washing step with EDTA removes the coordinated $\mathrm{Zn}^{\mathrm{II}}$ or $\mathrm{Cd}^{\mathrm{II}}$ ions and accordingly destroys the cluster(s) to a large extent, the major drawback of this method is oxidation of the MT requiring reduction of the apoprotein and metal ion reconstitution after purification. The second purification-tag used is the larger self-cleavable intein- tag (New England Biolabs, Ipswich, MA, USA). Overexpression of members of all four subfamilies is also possible in this system, although the yields are 3-5 times lower compared to the GST-tag. The advantage, however, is that the proteins can be obtained directly in their fully metal ion loaded forms, either with $\mathrm{Zn}^{\text {II }}$ or with $\mathrm{Cd}^{\mathrm{II}}$ ions.[6,37-39] We also attempted the purification of plant MTs without the use of purification tags. Using a slight modification of the protocol for the isolation of vertebrate MTs from E. coli, we were indeed able to purify wheat $\mathrm{Zn} \mathrm{E}_{6}-1$ in high yield. ${ }^{[11]}$ However, for members from subfamilies $\mathrm{p} 1, \mathrm{p} 2$, and $\mathrm{p} 3$ this procedure was not successful. Whether this is due to the different solubilities of the proteins under the purification conditions or indeed caused by proteolytic cleavage in $E$. coli is unclear.

Whether a purification tag was used or not, the final polishing step is always performed with size-exclusion chromatography. Considering the size of plant MTs, a Sephadex G-75 column proved to be most suited, and the purified monomeric proteins generally elute in a single well-resolved peak (Fig. 5A). A first fast method to roughly validate the correct molecular mass of the overexpressed protein is sodium dodecyl sulfate polyacrylamide gel electrophoresis, SDS-PAGE. For this, samples are denatured with SDS adding a certain negative charge to the protein proportional to its molecular mass and hence allowing the mass separation of a protein mixture by electrophoresis. For most MTs however, denaturation is incomplete and hence loading with SDS occurs substoichiometrically, because the metal-thiolate clusters stay intact under the conditions applied resulting in higher apparent molecular masses as depicted in Fig. 5B (left lane). Modification of thiolate groups, e.g. with monobromobimane $(\mathrm{mBBr}),{ }^{[40]}$ prior to SDS-PAGE destroys the clusters and allows a more reliable mass estimation (right lane).

The identity of the MT under investigation can be verified with ESI-MS of the apo-form at $\mathrm{pH}$ 2. Slightly more complex are measurements of the holo-forms acquired around pH 7.5 (Fig. 5C). The sensitivity of the measurement is reduced under these conditions but can reveal the metal ion binding ability of the protein. Great care has to be taken, however, not to miss binding sites with lower affinity. In the example depicted, the multiple peaks result from posttranslational protein modifications and are not due to impurities (peaks denoted with * and \# in Fig. 5C). ${ }^{[41]}$ These kinds of 'protein inhomogeneities' are not of relevance for most analyses and do not affect the metal ion binding abilities. Nevertheless, ways to prevent them are available if required. 


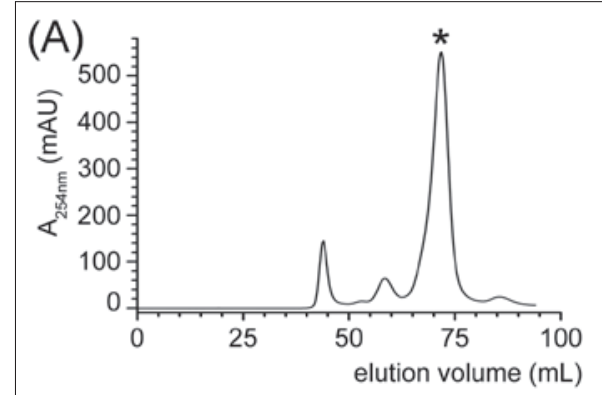

(B)

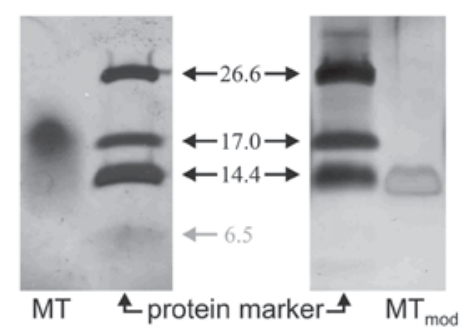

(C)

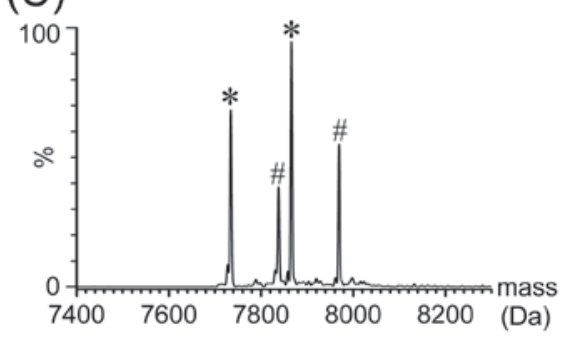

Fig. 5. Purification and purity control of recombinantly overexpressed plant MTs. (A) Typical elution profile of the final purification step with size exclusion chromatography (Sephadex G-75). The main peak, denoted with ${ }^{*}$, contains the desired protein. (B) SDS-PAGE of the MT after size exclusion chromatography (MT), and the same protein after modification with $\mathrm{mBBr}\left(\mathrm{MT}_{\text {mod }}\right)$. Apparent molecular masses of the protein marker bands are given in $\mathrm{kDa}$. (C) Typical ESI-MS spectrum of a metal ion loaded MT isoform acquired at $\mathrm{pH} 7.5$. Figure adapted from refs $[31,37]$ with kind permission of The Royal Society of Chemistry and Springer Science+Business Media.

\section{Analytical Methods}

\subsection{Protein and Metal Ion Concen- trations}

To report the metal ion content of a protein, the protein as well as the metal ion concentration needs to be determined. While most plant MTs contain a small number of aromatic amino acids, the amount is usually not sufficient to allow the exact quantification of the protein via its absorption at $280 \mathrm{~nm}$. Significantly more reliable results are obtained based on the $-\mathrm{SH}$ content of the reduced protein. The common assays used for the quantification of thiols make use of their quantitative reaction with activated aromatic disulfides. For example, the reaction with 2,2'-dithio-dipyridine (2PDS) yields free 2-thiopyridinone in stoichiometric amounts, which can be quantified with UV-spectroscopy via its spe- cific absorptivity $\left(\varepsilon_{343}=7600 \mathrm{M}^{-1} \mathrm{~cm}^{-1}\right)$. The reaction is typically performed in 0.2 $\mathrm{M}$ sodium acetate buffer, $\mathrm{pH} 4.0$, using a 2-PDS concentration of $100 \mu \mathrm{M}$ and consequently $-\mathrm{SH}$ concentration in the range 20-75 $\mu$ M. Alternatively, 5,5'-dithio-bis(2nitrobenzoic acid) (DTNB) has been used. Both assays can be performed with the $\mathrm{Zn}^{\mathrm{II}}$ - and $\mathrm{Cd}^{\mathrm{II}}$-forms of the respective MTs without loss of accuracy. Metal ion concentrations are usually assessed with flame-atomic absorption spectrometry (F-AAS) in $0.2 \mathrm{M}$ nitric acid. No further digestion of the protein matrix is required. Metal ion contents can of course also be directly assessed with ESI-MS spectrometry at neutral or slightly basic $\mathrm{pH}$ (see above) or with ICP-OES or -MS.

The contents of monovalent as well as divalent metal ions that can be accommodated in the different plant MT forms were recently summarized, and comparing the new results from careful recombinantly overexpressed proteins to previously known values it is fair to say that the basis for new and continuing research in this area could be laid. ${ }^{[30,31]}$

\subsection{Optical Spectroscopy}

From the area of optical spectroscopy, UV-vis spectroscopy certainly earns the highest status with respect to easy and fast applicability, low sample consumption and wealth of information to be gained. Plant MTs lend themselves to be studied by UVvis spectroscopy due to the specific charge transfer bands of the metal-thiolate clusters. These bands originate largely from ligandto-metal charge transfers (LMCT) involving the metal s orbitals, but also additional contributions from lower energy requiring ligand to ligand - or intraligand - charge transfer (LLCT) transitions, namely from sulfur to antibonding $\mathrm{p}_{\pi}$ orbitals within thiolates have been reported. ${ }^{[42,43]}$ As depicted in Fig. 6A,B the UV spectra of apo-MTs are featureless below $\sim 240 \mathrm{~nm}$ apart from contributions of the aromatic amino acids phenylalanine and tyrosine in some of the plant forms. In the holo-forms, the $\mathrm{S} \rightarrow \mathrm{Zn}^{\text {II }}$ LMCT bands cause a slight shoulder of the intense absorptions from the peptide backbone amide bands, while the corresponding $\mathrm{S} \rightarrow \mathrm{Cd}^{\mathrm{II}}$ bands are visible as a pronounced shoulder at $\sim 250 \mathrm{~nm}$. The clear separation of the $\mathrm{S} \rightarrow \mathrm{Zn}^{\mathrm{II}}$ and $\mathrm{S} \rightarrow \mathrm{Cd}^{\mathrm{II}}$ LMCT bands allows the isostructural replacement reaction of $\mathrm{Zn}^{\text {II }}$ by $\mathrm{Cd}^{\mathrm{II}}$ ions to be studied with UV spectroscopy in a simple titration experiment. Moreover, as the apparent stability of $\mathrm{Cd}^{\mathrm{II}}$ ions to MTs is by about $\sim 3-4$ $\log$ units larger than that of $\mathrm{Zn}^{\mathrm{II}}$ ions this reaction proceeds readily and virtually to completeness. Hence such an experiment offers an alternative fast and straightforward method to analyse the binding ability for divalent metal ions without requiring the metal ion concentration to be determined directly: The $\mathrm{Zn}^{\mathrm{II}}$-form is titrated stepwise with $\mathrm{Cd}^{\mathrm{II}}$ ions and the evolving $\mathrm{S} \rightarrow \mathrm{Cd}^{\mathrm{II}}$ LMCT band monitored until the UV spectra remain constant and hence the MT is saturated with $\mathrm{Cd}^{\mathrm{II}}$ ions. ${ }^{[6,37-39]}$ Other metal ions such as $\mathrm{Hg}^{\mathrm{II}}$ and $\mathrm{Cu}^{\mathrm{I}}$ and even more pronounced $\mathrm{Co}^{\mathrm{II}}$ and $\mathrm{Pb}^{\mathrm{II}}$ bring about transitions of even lower energies. Hence it is, e.g., also possible to titrate a Cd ${ }^{\mathrm{II}}$-MT with $\mathrm{Hg}^{\text {II }}$ ions without significant spectral overlap if for example the absorption at 320 $\mathrm{nm}$ is monitored. Naturally, the titration of, e.g., a $\mathrm{Zn}^{\mathrm{II}}-\mathrm{MT}$ with $\mathrm{Co}^{\mathrm{II}}$ ions will not succeed as the stability of metal-thiolate coordination follows largely the Irving-Williams row and therefore $\mathrm{Co}^{\mathrm{II}}$ ions will not be able to replace the coordinated $\mathrm{Zn}^{\mathrm{II}}$ ions. For such cases, metal ion reconstitution reactions have to be performed starting from
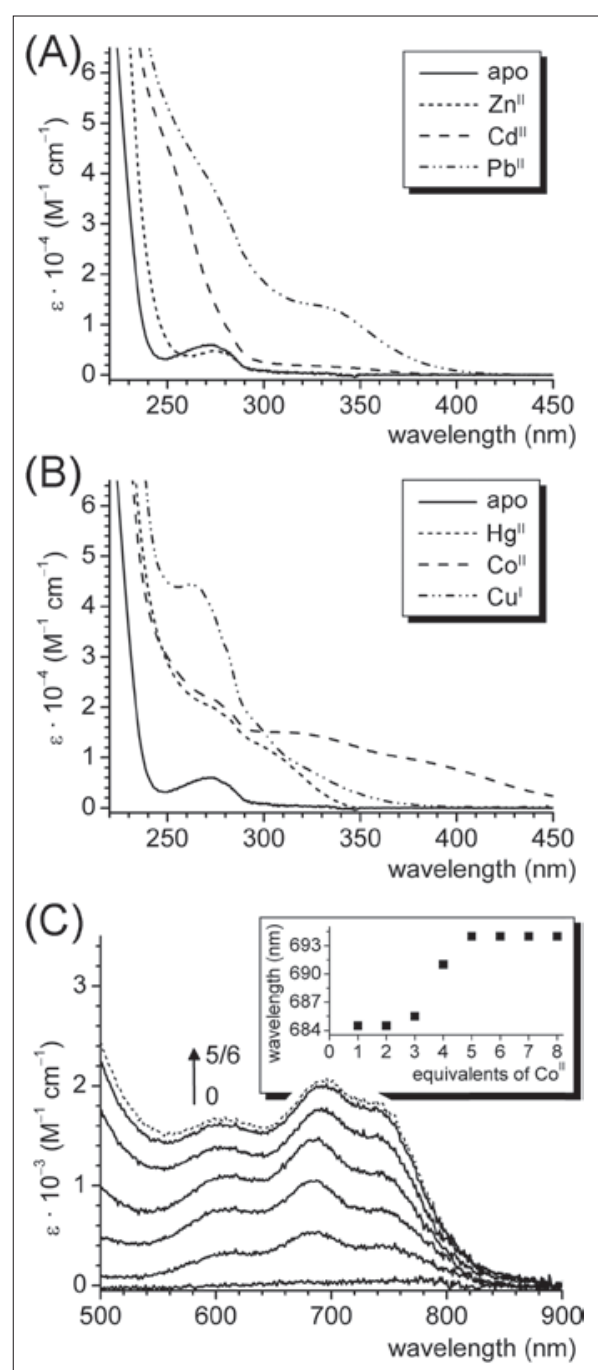

Fig. 6. (A, B) UV absorption spectra of a plant MT containing aromatic amino acids showing typical examples of LMCT bands in the range of $230-450 \mathrm{~nm}$ for the indicated metal ions. (C) Absorption spectra of chickpea $\mathrm{Co}_{0-5} \mathrm{MT} 2$ showing the typical $d-d$ transitions. Clearly the increase in absorptivity but also the shift during cluster formation ( $4-5$ equiv.) can be seen (inset). 
the apo-form under strictly anaerobic conditions, preferable in an anaerobic chamber. Reconstitution experiments with $\mathrm{Co}^{\mathrm{II}}$ are, among others, very valuable as they provide insights into the cluster formation process. Especially the $d$ - $d$ transitions of $\mathrm{Co}^{\mathrm{II}}$ in a tetrahedral tetrathiolate coordination sphere are extremely sensitive to changes in the coordination environment. As a result, the respective CT bands will, in addition to an increase in absorptivity, also show shifts of their absorption maxima when sufficient $\mathrm{Co}^{\mathrm{II}}$ ions were added to start the cluster formation process (Fig. 6C). ${ }^{[37,39,44]}$

A second very versatile method from the field of optical spectroscopy is circular dichroism (CD). In contrast to the rather unresolved transitions in the UV spectra the ellipticity bands observed with $\mathrm{CD}$ spectroscopy are generally much more distinct. The spectra of MTs above 240 $\mathrm{nm}$, and hence above the range indicative for secondary structural elements of the peptide backbone, are dominated by the extrinsic Cotton effects brought about by the metal-thiolate clusters. As a result, formation of local ellipticity maxima and minima as well as shifts of ellipticity bands upon metal ion binding or in response to external factors such as $\mathrm{pH}$, ionic strength, and temperature can provide supplementary information about metal-thiolate cluster formation, break-up, or rearrangements. Moreover, upon addition of a surplus of metal ions we were able to observe spectral changes with $\mathrm{CD}$ and hence structural changes that went undetected with UV spectroscopy. Supplementary experiments revealed the presence of an additional metal ion binding site with reduced stability.[11] The highly interesting question if this additional binding site is UV-silent because other ligands than thiolate groups are recruited or because coordination requires solely bridging thiolate ligands, or a mixture of both, is awaiting further analysis.

\subsection{Biochemical Methods}

Examination of the unique amino acid sequences of plant MTs with their clustered Cys-rich regions always prompts for the same question: How many different clusters are formed? Members of the p1, p2, and p3 subfamilies have two Cys-rich regions and hence could form two separate metal-thiolate clusters. It is, however, also feasible that the Cys residues of the entire protein are joined by just one single larger cluster. This ambiguity was early addressed and partially resolved for garden pea MT1. Limited proteolytic digestion of the protein with proteinase $\mathrm{K}$, a subtilisin-related fungal protease, followed by size-exclusion chromatography of the digestion mixture yielded a single peak fraction containing both Cys-rich regions but not the linker region. ${ }^{[35]}$ This allows the assumption that in pea MT1 the $\mathrm{N}$ - and C-terminal Cys-rich regions are connected by a single metal-thiolate cluster. Recently, we obtained a similar result for Cicer arietinum (chickpea) MT2. [39] Also here, both Cys-rich regions stay associated with each other even after partial proteolytic digestion of the peptide backbone and removal of the linker region. In this protein, presumably an aggregate of the composition $\mathrm{Cd}_{5} \mathrm{Cys}_{14}$ is formed. Less unambiguous is the situation with a member of the p3 subfamily, Musa acuminata (banana) MT3. This protein can form species with three or four $\mathrm{Zn}^{\mathrm{II}}$ or $\mathrm{Cd}^{\mathrm{II}}$ ions. ${ }^{6]}$ Purely arithmetically speaking, three divalent metal ions could be accommodated in two separate clusters, while coordination of four metal ions would require more bridging thiolate groups and hence a single larger cluster. That this might be actually the case is suggested by measurements with dynamic light scattering: The hydrodynamic radius of the $\mathrm{Zn}_{3} \mathrm{MT} 3$ species was found to be significantly larger than the radius of $\mathrm{Zn}_{4} \mathrm{MT} 3$ indicating an elongated two-cluster structure versus a more globular one-cluster arrangement. Finally, limited proteolytic digestion experiments laid the basis for our further investigations of the separate domains of wheat $\mathrm{Zn}_{6} \mathrm{E}_{\mathrm{c}}-1$.
We could clearly show that the N-terminal Cys-rich region forms a separate domain, presumably harbouring a $\mathrm{Zn}_{2} \mathrm{Cys}_{6}$ cluster, while the central and $\mathrm{C}$-terminal Cys-rich regions are joined by four $\mathrm{Zn}^{\text {II }}$ ions. [37]

\subsection{X-Ray Spectroscopy}

Since early on there was the question if His residues play a role in metal ion binding in certain plant MTs. In the cyanobacterial MT SmtA a $\mathrm{Zn}_{4} \mathrm{Cys}_{9} \mathrm{His}_{2}$ cluster is formed, while the single His residue in the yeast CUP1 protein does not take part in the coordination of the $\mathrm{Cu}^{\mathrm{I}}$ ions (Fig. 3). ${ }^{[19,25]}$ In the absence of structural data, X-ray spectroscopy can provide useful information. In particular, we performed extended X-ray absorption fine structure (EXAFS) measurements to investigate the contribution of the two highly conserved His residues to the coordination of the $\mathrm{Zn}^{\text {II }}$ ions in wheat $\mathrm{E}_{\mathrm{c}}-1$ (Fig. 7). ${ }^{[11]}$ For the fulllength protein, results clearly showed some amount of His contribution. However, as EXAFS is only able to report average coordination spheres in a protein binding multiple identical metal ions, the differentiation between an average $\mathrm{ZnCys}_{3.83} \mathrm{His}_{0.17}$ (contribution of one His) or $\mathrm{ZnCys}_{3.67} \mathrm{His}_{0.33} \mathrm{co}-$ ordination (contribution of both His) was not possible considering the error range of the measurement. In contrast, when using

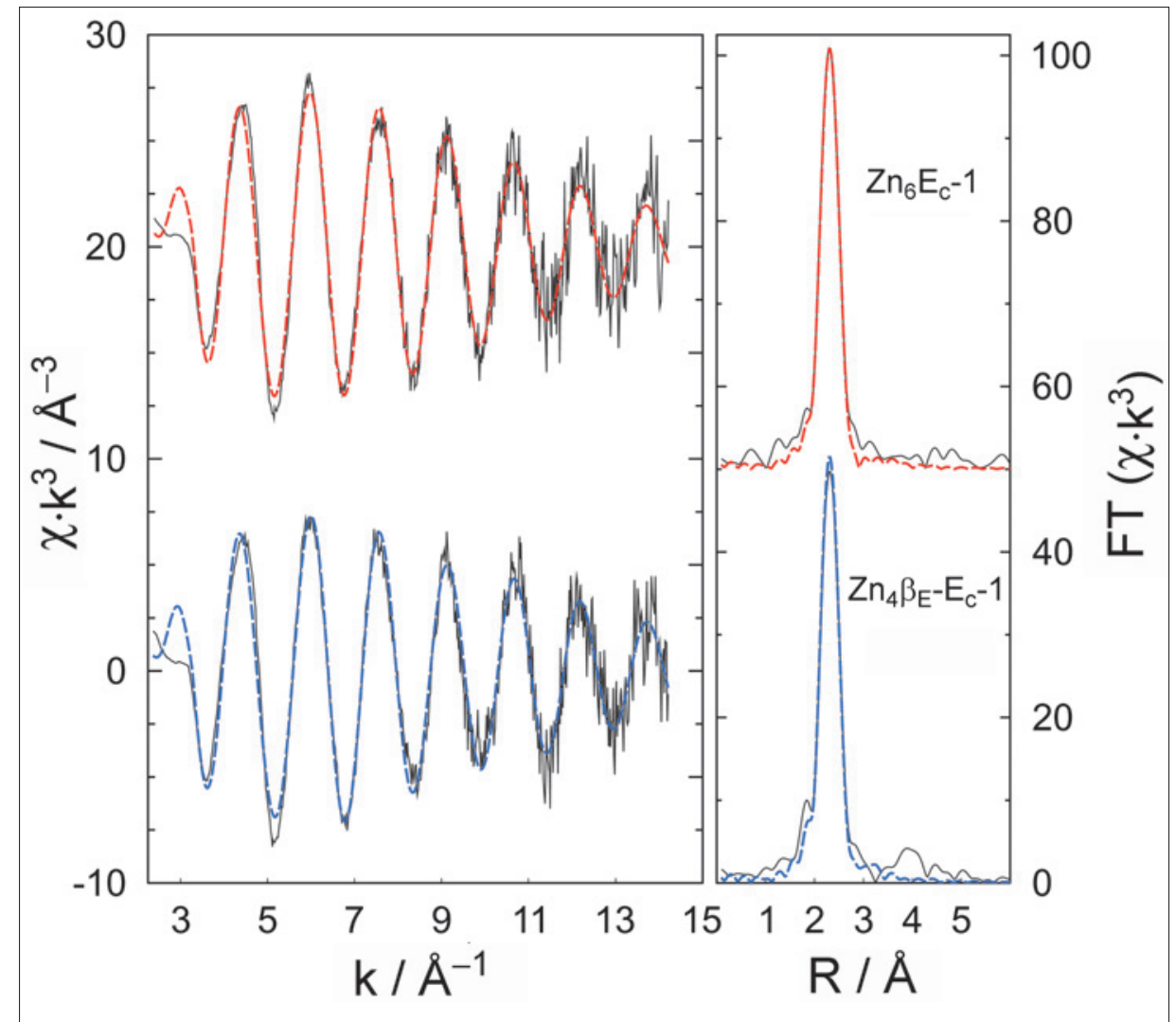

Fig. 7. EXAFS (left) and corresponding Fourier transform (right) of $Z n_{6} E_{c}-1$ (top) and $Z n_{4} \beta_{E} E_{c}-1$ (bottom). The EXAFS is dominated by a single frequency, originating from sulfur backscattering. Introducing small His contributions in the refinement at $1.9 \AA$ improves the fit. The simulated signals (dashed lines) are drawn superimposed on the experimental data (solid lines), respectively. Figure taken from ref. [11] with kind permission from Elsevier. 
only the larger domain of wheat $\mathrm{E}_{\mathrm{c}}-1$ for the measurement, the differentiation between $\mathrm{ZnCys}_{375} \mathrm{His}_{025}$ (contribution of one His) or $\mathrm{ZnCys}_{35} \mathrm{His}_{0.5}$ coordination (contribution of both His) could be made and clearly revealed that both His residues are directly involved in $\mathrm{Zn}^{\mathrm{II}}$ binding.

\subsection{NMR Spectroscopy}

The low molecular masses of MTs permit structure determination with NMR spectroscopy. Our experience with plant MTs however shows that many forms initially yield spectra with broad signals and hence a resolution too low to allow structure calculations. Sometimes, the signal dispersion of such samples can be improved by tedious optimization of, e.g., protein buffer conditions, parameters such as acquisition temperature, or even by manipulations of the protein sequence such as shortening of flexible linker regions or

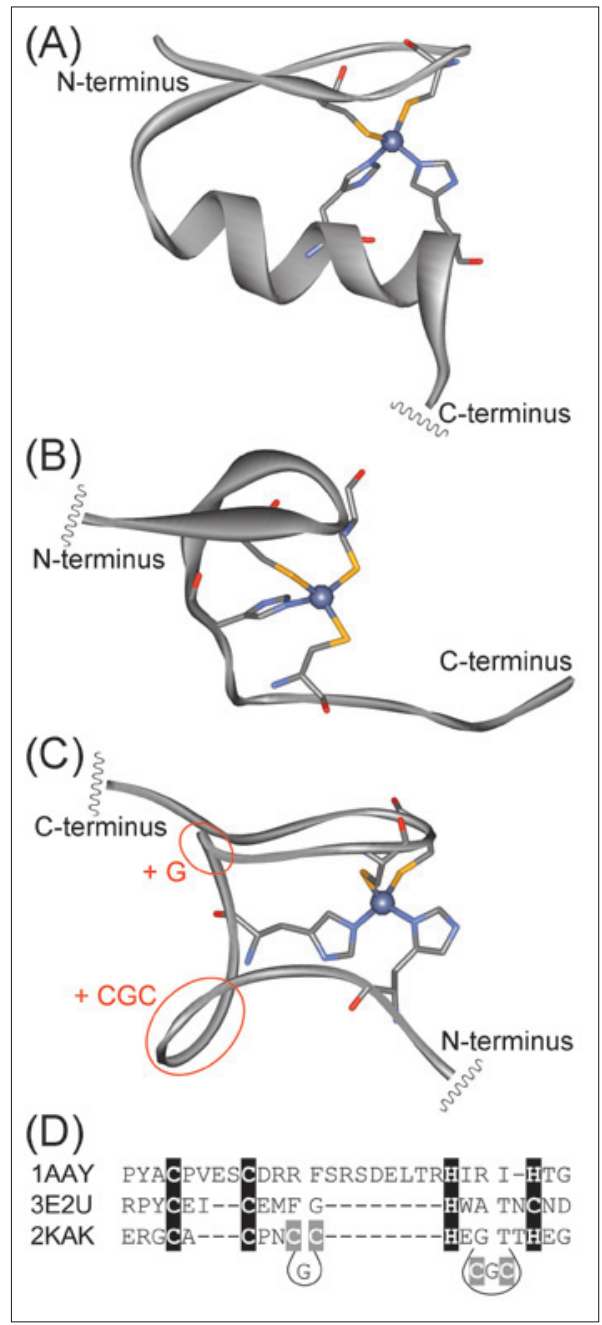

Fig. 8. Three-dimensional structures of $(A)$ a $\mathrm{Zn}$ finger domain (Zif268, PDB code 1AAY), ${ }^{[46]}$ (B) a Zn knuckle motif (CLIP170, 3E2U), ${ }^{[45]}$ and (C) the mononuclear $\mathrm{ZnCys}_{2} \mathrm{His}_{2}$ site in wheat $\mathrm{Zn}_{6} \mathrm{E}_{\mathrm{c}}-1$ (2KAK). ${ }^{[23]}$ (D) Sequence alignment of the depicted structures with Cys and His residues highlighted. Cys residues highlighted in grey in sequence $2 \mathrm{KAK}$ do not take part in coordination of the depicted $\mathrm{Zn}^{\|}$ion.

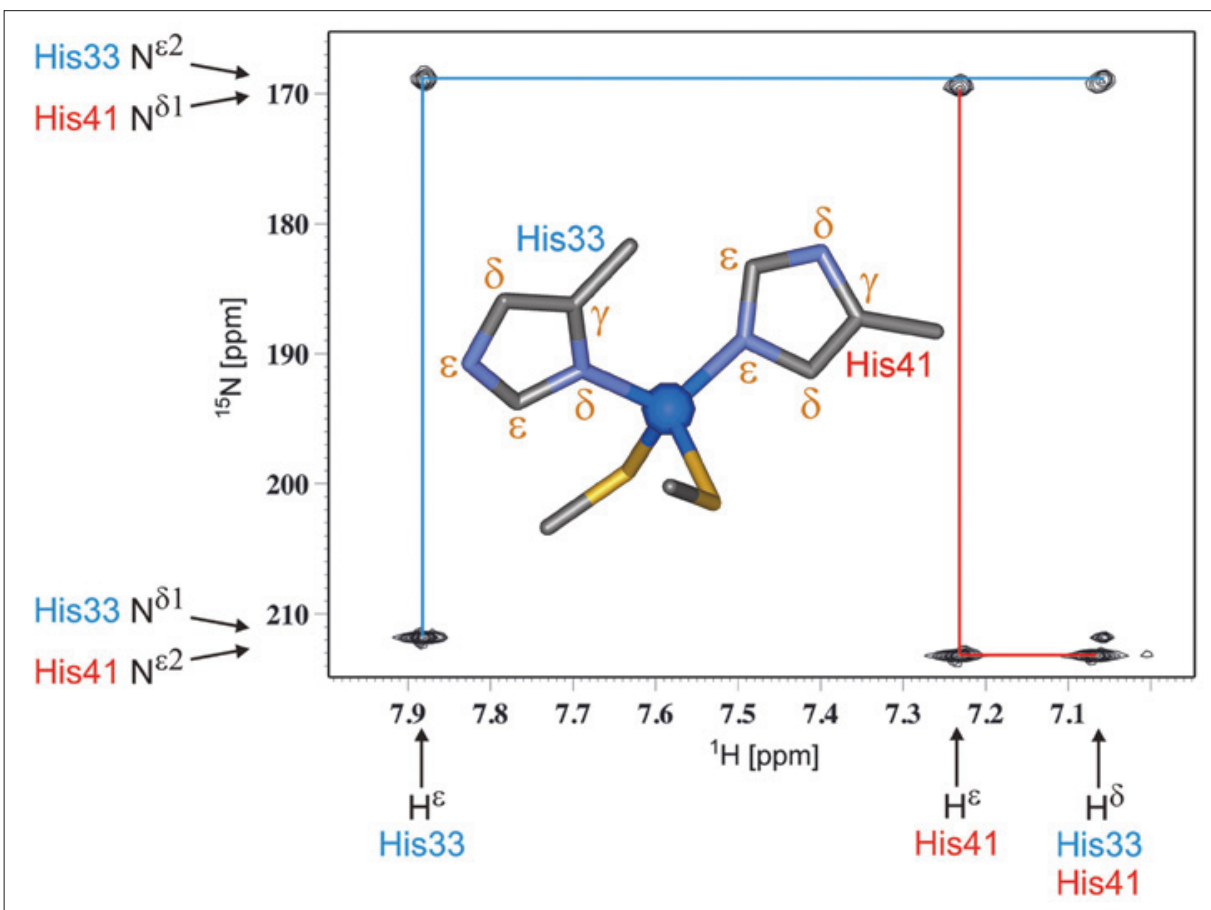

Fig. 9. 2D long-range $\left[{ }^{15} \mathrm{~N},{ }^{1} \mathrm{H}\right] \mathrm{HSQC}$ of $\mathrm{Zn}_{4} \beta_{\mathrm{E}}-\mathrm{E}_{\mathrm{c}}-1$ to determine the tautomeric forms of the two His ligands with annotated peak assignment. Figure adapted from ref. [23] with kind permission from Elsevier.

the analysis of separate domains. The first three-dimensional structure of a plant MT was recently determined in our group, i.e. the solution structure of the larger domain from the wheat $\mathrm{Zn}_{6} \mathrm{E}_{\mathrm{c}}-1$ protein, $\mathrm{Zn}_{4} \beta_{\mathrm{E}}-\mathrm{E}_{\mathrm{c}}-1$ (Fig. 3C). ${ }^{[23]}$ This naturally $\mathrm{Zn}^{\text {II }}$ binding protein shows a structure unprecedented for MTs so far. While a $\mathrm{Zn}_{3} \mathrm{Cys}_{9}$ cluster can be found with similarity to the $\beta$-clusters of vertebrate, crustacean, and echinodermata MTs, an additional mononuclear $\mathrm{ZnCys}_{2}$ His 2 site is observed, which is absolutely unique. Such sites are well known from $\mathrm{Zn}$ finger proteins, which bind to certain DNA sequences and play a role in gene regulation (Fig. 8A). The name of these domains is derived from the finger-like loop that usually contains also a $\alpha$-helical motif and is stabilized by the coordinated $\mathrm{Zn}^{\mathrm{II}}$ ion. A less well-described motif is the related $\mathrm{Zn}$ knuckle domain, which can be found $e . g$. in CLIP170, a microtubule plus end-binding protein (Fig. 8B). ${ }^{[45]}$ As can be clearly seen, the name of this motif reflects the reduction of the finger-like loop structure to a mere 'knuckle'. Comparing the structure around the mononuclear site found in $\mathrm{Zn}_{4} \beta_{\mathrm{E}}-\mathrm{E}_{\mathrm{c}}-1$ to the above motifs, it clearly resembles more a knuckle than a finger. If part of the additional residues required for the formation of the neighbouring $\mathrm{Zn}_{3} \mathrm{Cys}_{9}$ cluster is removed from the sequence, the sequences of the $\mathrm{Zn}$ knuckle domain and the corresponding part in $\mathrm{Zn}_{4} \beta_{\mathrm{E}}-\mathrm{E}_{\mathrm{c}}-1$ can be very well aligned. However, the possibility that this similarity is reflected in some way also in the functions of these proteins is more than just a vague hypoth- esis considering the current state of knowledge.

NMR spectroscopy also enables additional insights into the metal clusters of plant MTs. For example, two-dimensional correlation spectra such as $\left[{ }^{113} \mathrm{Cd},{ }^{113} \mathrm{Cd}\right]$ COSY allow direct coupling of metal ions to be observed and hence help to identify metal-metal connectivities in the clusters. Proton-metal couplings in $\left[{ }^{1} \mathrm{H},{ }^{113} \mathrm{Cd}\right]$ HMQC experiments allow the assignment of metal ions to their coordinating ligands and are a possibility to reveal $e . g$. bridging thiolate groups. To identify His coordination of metal ions a 2D long-range $\left[{ }^{15} \mathrm{~N},{ }^{1} \mathrm{H}\right]-\mathrm{HSQC}$ experiment can be used (Fig. 9).[23,47] The observed chemical shifts of the resonances are a strong indication for the prevailing His tautomer and thus can be used to identify the metal ion coordinating ring nitrogen.

\subsection{Other Methods}

The combination of being small proteins and containing an 'inorganic' metalthiolate core renders MTs typical examples from the field of bioinorganic chemistry. The sections above already show that techniques from both, analytical inorganic chemistry and biochemistry can be applied to decipher the properties and structures of this kind of proteins in more detail. Some additional versatile methods will be exemplified in the following. To determine the amount of secondary structural elements next to CD spectroscopy also IR spectroscopy can be applied. Fluorescence spectroscopy can be used to study protein fold- 
ing after site-specific insertion of appropriate fluorescence labels. This method is also useful to determine stability constants of metal ion binding, as are isothermal titration calorimetry (ITC) or competition reactions with selected metal ion chelators. Finally, EPR spectroscopy of $\mathrm{Ni}^{\mathrm{II}}$ and $\mathrm{Co}^{\mathrm{II}}$ containing MTs has been used to follow the metal-thiolate cluster formation process.

\section{Further Directions}

After initial characterisation of a new plant MT, the main focus is usually set on the determination of its three-dimensional structure, either with NMR spectroscopy or with X-ray crystallography. With knowledge of the structure as a basis, structure-function relationships can be deduced. Targeted protein manipulations can be performed to alter characteristics and to reassess the hypotheses made. An important future task will be the identification of possible binding partners, be it other proteins, nucleic acids, or smaller non-protein metal ion chelators. It is also of interest to study the dynamics of these proteins in more detail, i.e. how are metal ions taken up or released from plant MTs. Being still at the beginning of plant MT research, a whole new exciting research field is opening up, and we can look forward to further stunning discoveries about MTs, which at one time were even thought to offer no more new insights.

\section{Acknowledgements}

Acknowledgements go to all past and present group members for their hard work and enthusiasm, as well as to many colleagues and friends for very fruitful collaborations. Continuous financial support from the Swiss National Science Foundation (SNFFörderungsprofessur and direct project funding), the Institute of Inorganic Chemistry, and the Faculty of Science of the University of Zürich is gratefully acknowledged.

Received: February 16, 2010
[1] C.-C. Chang, S.-F. Lee, K.-W. Sun, C.-C. Ho, Y.-T. Chen, C.-H. Chang, L.-S. Kan, Biochem. Biophys. Res. Commun. 2006, 340, 1134.

[2] M. Good, M. Vašák, Biochemistry 1986, 25 , 8353.

[3] M. Good, M. Vašák, Biochemistry 1986, 25, 3328.

[4] M. Vašák, J. H. R. Kägi, B. Holmquist, B. L. Vallee, Biochemistry 1981, 20, 6659 .

[5] A. V. Karotki, M. Vašák, J. Biol. Inorg. Chem. 2009, 14, 1129

[6] E. Freisinger, Inorg. Chim. Acta 2007, 360, 369.

[7] M. E. Merrifield, T. Ngu, M. J. Stillman, Biochem. Biophys. Res. Commun. 2004, 324 127.

[8] H. Willner, M. Vašák, J. H. R. Kägi, Biochemistry 1987, 26, 6287.

[9] K. E. R. Duncan, M. J. Stillman, FEBS J. 2007, 274, 2253

[10] P. M. Gehrig, C. H. You, R. Dallinger, C. Gruber, M. Brouwer, J. H. R. Kägi, P. E. Hunziker, Protein Sci. 2000, 9, 395.

11] E. A. Peroza, A. Al Kaabi, W. Meyer-Klaucke, G. Wellenreuther, E. Freisinger, J. Inorg. Biochem. 2009, 103, 342.

[12] J. N. Chan, Z. Y. Huang, M. E. Merrifield, M. T. Salgado, M. J. Stillman, Coordin. Chem. Rev. 2002, 233, 319 .

[13] L. A. Ba, M. Doering, T. Burkholz, C. Jacob, Metallomics 2009, 1, 292.

[14] Y. Uchida, K. Takio, K. Titani, Y. Ihara, M. Tomonaga, Neuron 1991, 7, 337.

[15] L. R. Kelland, P. Mistry, G. Abel, F. Freidlos, S Y. Loh, J. J. Roberts, K. R. Harrap, Cancer Res. 1992, 52, 1710

[16] P. J. Thornalley, M. Vašák, BBA-Protein Struct. M. 1985, 827, 36

[17] L. J. Jiang, W. Maret, B. L. Vallee, Proc. Natl. Acad. Sci. USA 1998, 95, 3483.

[18] W. Braun, M. Vašák, A. H. Robbins, C. D Stout, G. Wagner, J. H. R. Kägi, K. Wüthrich, Proc. Natl. Acad. Sci. USA 1992, 89, 10124.

[19] V. Calderone, B. Dolderer, H. J. Hartmann, H. Echner, C. Luchinat, C. Del Bianco, S. Mangani, U. Weser, Proc. Natl. Acad. Sci. USA $\mathbf{2 0 0 5}, 102,51$

[20] K. H. Gardner, S. F. Anderson, J. E. Coleman, Nat. Struct. Mol. Biol. 1995, 2, 898.

[21] J. D. Baleja, V. Thanabal, G. Wagner, J. Biomol. NMR 1997, 10, 397

[22] A. Muñoz, F. H. Försterling, C. F. Shaw III, D. H. Petering, J. Biol. Inorg. Chem. 2002, 7, 713.

[23] E. A. Peroza, R. Schmucki, P. Güntert, E. Freisinger, O. Zerbe, J. Mol. Biol. 2009, 387, 207.

[24] R. Riek, B. Prêcheur, Y. Wang, E. A. Mackay, G. Wider, P. Güntert, A. Liu, J. H. R. Kägi, K. Wüthrich, J. Mol. Biol. 1999, 291, 417.

[25] C. A. Blindauer, M. D. Harrison, J. A. Parkinson, A. K. Robinson, J. S. Cavet, N. J. Robinson, P. J. Sadler, Proc. Natl. Acad. Sci. USA 2001, 98, 9593.
[26] J. H. R. Kägi, B. L. Vallee, J. Biol. Chem. 1960, $235,3460$.

[27] L. Hanley-Bowdoin, B. G. Lane, Eur. J. Biochem. 1983, 135, 9.

[28] B. G. Lane, R. Kajioka, T. D. Kennedy, Biochem. Cell Biol. 1987, 65, 1001.

[29] C. Cobbett, P. Goldsbrough, Annu. Rev. Plant Biol. 2002, 53, 159.

[30] E. Freisinger, Dalton Trans. 2008, 6663.

[31] E. Freisinger, Met. Ions Life Sci. 2009, 5, 107.

[32] W. J. Guo, W. Bundithya, P. B. Goldsbrough, New Phytol. 2003, 159, 369.

[33] S. N. A. Abdullah, S. C. Cheah, D. J. Murphy, Plant Physiol. Bioch. 2002, 40, 255.

[34] W.-J. Guo, M. Meetam, P. Goldsbrough, Plant Physiol. 2008, 146, 1697.

[35] P. Kille, D. R. Winge, J. L. Harwood, J. Kay, FEBS Lett. 1991, 295, 171

[36] D. A. Polayes, T. D. Parks, S. A. Johnston, W. G. Dougherty, Methods Mol. Med. 1998, 13, 169.

[37] E. A. Peroza, E. Freisinger, J. Biol. Inorg. Chem. 2007, 12, 377

[38] O. Schicht, E. Freisinger, Inorg. Chim. Acta 2009, 362, 714

[39] X. Wan, E. Freisinger, Metallomics 2009, 1, 489.

[40] G. Meloni, M. Knipp, M. Vašák, J. Biochem. Bioph. Meth. 2005, 64, 76.

[41] E. A. Peroza, E. Freisinger, Protein Expres. Purif. 2008, 57, 217.

[42] H.-J. Liu, J. T. Hupp, M. A. Ratner, J. Phys. Chem. 1996, 100, 12204.

[43] E. I. Solomon, S. I. Gorelsky, A. Dey, J. Comp. Chem. 2006, 27, 1415.

[44] M. Vašák, J. H. R. Kägi, Proc. Natl. Acad. Sci. USA 1981, 78, 6709

[45] A. Weisbrich, S. Honnappa, R. Jaussi, O. Okhrimenko, D. Frey, I. Jelesarov, A. Akhmanova, M. O. Steinmetz, Nat. Struct. Mol. Biol. 2007, 14, 959 .

[46] M. Elrod-Erickson, M. A. Rould, L. Nekludova, C. O. Pabo, Structure 1996, 4, 1171.

[47] K. Kwon, C. Y. Cao, J. T. Stivers, J. Biol. Chem. 2003, 278, 19442. 